\title{
A escritura indígena canadense contemporânea: um ato de tradução intercultural1
}

\author{
Contemporary Native Canadian writing: an act of cross-cultural translation
}

Eloína Prati dos Santos

Núcleo de Estudos Canadenses - Universidade Federal do Rio Grande do Sul - Porto Alegre - Rio Grande do Sul - Brasil $\diamond$

\begin{abstract}
Resumo: Este artigo apresenta um panorama da literatura indígena contemporânea no Canadá inglês, procurando mostrar a crítica ao sistema colonial e seus resquícios atuais, através da sugestão de novas definições de gênero, da autoficção, em figuras como a do trickster, no uso de línguas tribais e em outras estratégias que têm contribuído para a "indianização" da literatura canadense e para a abertura do cânone eurocanadense.
\end{abstract}

Palavras-chave: Literatura indígena canadense contemporânea

\begin{abstract}
This essay presents na overview of contemporary Native literature in English Canada, trying to show its criticism of the colonial system and its current vestiges in the proposal of new genre definitions, in autofiction, in figures as the trickster, in the use of tribal languages and in other strategies that have been contributing to the "indianization" of Canadian literature and to the opening of the Euro-Canadian canon.
\end{abstract}

Keywords: Contemporary Native Canadian literature

Sinto-me um pouco como Zola, fazendo proclamações políticas e agora literárias a partir de um sentido de realidade que outros humanos não necessariamente compartilham. ${ }^{2}$

(LeE MARACLE)

Os povos nativos do continente americano passaram por um longo e progressivo período de apagamento de sua memória cultural desde os primeiros encontros, anteriores ao processo colonial, com viajantes, cientistas e aventureiros europeus. Com o início do ciclo colonial se aprofunda o processo ambíguo de idealização ou de demonização dos povos ameríndios, cuja imagem vai ficando presa na dicotomia entre a visão do "novo mundo" como um paraíso de natureza pródiga e povos acolhedores, adotada por viajantes e estudiosos da fauna e flora dessa nova parte do mundo, e a visão eurocentrista de que povos não brancos e não cristãos não teriam alma, seriam selvagens demoníacos, canibais perigosos, disseminadas tanto por representantes de

\footnotetext{
1 Empresto de Homi Bhabha a descrição dos teóricos nativo-americanos (1994, p. 228)

2 I feel a little like Zola, making political and now literary proclamations from within a sense of reality which other humans do not necessarily share. Tradução da autora.
}

governos que tinham interesse comercial em explorar o continente recém-descoberto, como por religiosos em missão evangelizadora. A miscigenação que começara antes do ciclo colonial e se dissemina com a instalação das colônias, combinada com a evangelização intensiva, fixam estes estereótipos.

Durante o ciclo colonial o apagamento das culturas indígenas se intensifica através de guerras, genocídios, desterritorialização forçada e interferência direta na vida tribal, como a proibição de certos rituais e a internação compulsória das crianças ameríndias em escolas do estado, principalmente nos Estados Unidos e no Canadá, onde passavam nove meses do ano longe de suas famílias e comunidades, falando apenas a língua europeia imposta, em violento plano de aculturação forçada que incluiu abuso psicológico, físico e sexual. Mesmo com diferenças locais, tribais, históricas e outras, considerando que os primeiros colonizadores foram principalmente ingleses, franceses, portugueses, espanhóis e holandeses, entre os 
quais os objetivos e métodos de colonização não foram uniformes, este processo atingiu, e ainda atinge todos os povos nativos do continente americano e foi devidamente registrado em cartas, diários, jornais e relatos da época, disponíveis a pesquisadores, indígenas e não indígenas que os têm revisitado na contemporaneidade, principalmente à luz das teorias pós-coloniais, em obras teóricas, críticas e literárias.

O processo civilizatório previa a extinção dos índios ou a superação da condição indígena pela aculturação. Nenhuma das alternativas se realizou, mas os preconceitos gerados no período colonial permanecem entre nós. $\mathrm{Na}$ segunda metade do século XX, a questão se amplia com o avanço do capitalismo financeiro e da globalização, processos que aprofundam a marginalização dos povos indígenas. Por outro lado, os povos indígenas se associaram aos movimentos por direitos civis, aumentado seu ativismo por reconhecimento, terras, soberania e valorização da mulher indígena.

Entre os séculos XVII a XIX, o ameríndio tornouse objeto de um vasto acervo literário escrito por não índios, que reflete não só os dois lados da dicotomia bom selvagem ou demônio - mas principalmente o retrata como uma raça moribunda e em processo de degeneração física e espiritual. O novo direcionamento formal e teórico da segunda metade do século XX, como o pós-moderno e pós-colonial, permitem um reexame dos pressupostos românticos e modernistas em relação ao ameríndio e isso proporciona o surgimento de uma literatura indigenista que revisita a literatura colonial e desencadeia uma crítica dos estereótipos vigentes na cultura ocidental. Essa atualização e expansão do romance indigenista também traz maior visibilidade à literatura produzida por Nativos contemporâneos, inteiramente sujeitos de sua representação, principalmente desde meados dos anos 1960 (ano do Prêmio Pulitzer concedido ao escritor nativo estadunidense Scott Momaday), e que abre mundos novos para os Nativos e para os não Nativos, para muito além dos clichês perpetuados desde o início do ciclo colonial.

Também é preciso considerar, como nos lembra Helen Hoy, "que a escrita, a edição, a publicação, a encenação, o ensino e a leitura da produção Nativa tem lugar, pelo menos parcialmente, em contextos controlados pelo poder discursivo e institucional da cultura dominante [no Canadá]. Comissões editoriais, agências de fomento, editora, comitês de premiação, currículos escolares e universitários e teorização e análises acadêmicas, atribuem mérito, distribuem recursos, tecem políticas de inclusão ou exclusão e produzem sentido baseados em normas extrínsecas ou mesmo inimigas dos valores e interesses indígenas. Tais efeitos não são acidentais ou simplesmente idiossincráticos" (2001, p. 13).
As Primeiras Nações ${ }^{3}$ canadenses, pelas diferenças climáticas, geográficas, linguísticas, entre outras, mantinham uma tradição oral baseada em histórias, mitos, cantos, rituais e cerimônias específicos de suas crenças e visão de mundo, definindo e reforçando a identidade tribal e comunitária. Várias dessas cerimônias, por serem participativas, acabaram proibidas desde o século XIX até a metade do século XX, entre elas a Sun Dance e o Potlatch. Após os movimentos por direitos civis dos anos 60 e 70, o governo canadense estabeleceu algumas políticas de reconhecimento do multiculturalismo que propiciaram uma revitalização das culturas nativas tradicionais. Com a oralidade reprimida e o reconhecimento apenas das culturas de língua escrita, um corpo cada vez mais genuíno de textos indígenas é publicado no Canadá, inicialmente em revistas literárias e antologias, e atualmente visível em todos os gêneros - poesia, teatro, romance, conto, autobiografia e não ficção, onde a autodefinição de suas identidades culturais expressa a realidade do que é ser índio hoje. Isso leva a reflexões sobre experiências como a exclusão, o racismo, a exploração, mas principalmente sobre a revitalização das culturas nativas do país dentro da sociedade contemporânea e ainda incorpora tradições orais que transformam a sintaxe, o ritmo e os temas da literatura euro-canadense, alargando e arejando a cultura e a história literária do Canadá na contemporaneidade. Como diz Chandra Mohanty, "é necessário admitir a 'coimplicação', a consciência das histórias, relações e responsabilidades assimétricas, mas mutuamente constitutivas" (1989-90, p. 194).

O que o processo colonial ocasionou foi complicar o conceito de raça, ao assumir que todo o escritor Nativo é o recipiente de todo o saber tribal não acessível aos não índios. O índio contemporâneo, aponta Thomas King, "mesmo com alguns denominadores comuns de raça, possui uma variada experiência de vida que inclui os de etnia pura criados nas cidades, os mestiços criados em fazendas, o quartos de sangue criados em reservas, índios adotados e criados por famílias brancas, índios que falam sua língua tribal e aqueles que só falam inglês, índios educados de forma tradicional e índios educados em universidades, índios com pouca educação formal e tudo mais que compartilhamos. Seria místico, romântico e até interesseiro pensar isso frente à quantidade de grupos de culturas e línguas Nativas

\footnotetext{
Não vamos nos deter na discussão sobre a terminologia mais adequada para referir os autores analisados aqui, mas usaremos "ameríndio" para designar todos os habitantes nativos do continente americano, índio como termo genérico (usado no Brasil pelos próprios autores indígenas e considerado um termo racista por alguns autores da América do Norte), além das referências tribais pelas quais eles se identificam, a preferida da maioria dos autores nativos do continente por fugir da homogeneização colonial. No Canadá a designação Primeiras Nações é oficialmente aquela que designa os seus povos nativos coletivamente.
} 
diversas e a variedade de condições de vida das tribos nos dias de hoje (1990, p. x, xi.)"4.

Thomas King (Cherokee-grego) declara o termo pós-colonial inaceitável em relação às literaturas indígenas. Ele chama o triunvirato - pré-colonial, colonial e pós-colonial - de "etnocentrismo não disfarçado" e "desconsideração bem intencionada". King coloca o problema do termo em seu "inescapável nacionalismo" e na "perigosa crença de que o ponto de partida se qualquer discussão é a chegada dos europeus à América do Norte". Ele completa acusando os estudos póscoloniais de organizarem a literatura progressivamente, "com a implicação de progresso e desenvolvimento", e de assumir que "o catalizador para a literatura indígena é a luta entre opressor e oprimido". Segundo King, a literatura pré-colonial não tem qualquer relação com a literatura colonial, "não fazem parte de um ciclo natural ou biológico, nem uma antecipa a outra. Assim, as literaturas indígenas contemporâneas não podem ser classificadas como pós-coloniais "pelo fato óbvio de que não há um 'pós' ao status colonial dos indígenas norte-americanos" (1990, p. 184).

King oferece ainda uma classificação de gênero específica para a literatura ameríndia que contempla essa literatura que se torna escrita e ao mesmo tempo permanece oral. Ele oferece os termos: "tribal", a literatura compartilhada quase exclusivamente pelos membros de uma comunidade, apresentada e conservada em uma língua nativa; "polêmica" refere-se à literatura em língua indígena ou em inglês, ou francês, que aborda o choque de culturas nativas e não nativas, defendendo os valores nativos contra os euroamericanos; "interfusional" King usa para descrever a literatura que funde literatura oral e escrita; e "associativa" é o corpus literário produzido por escritores nativos contemporâneos, em geral descrevendo uma comunidade ou conflito, concentrando-se nas complexidades da vida e da organização nativas como enredo principal (p. 185-187). Esta terminologia, segundo King, não privilegia uma cultura ou outra, boicota o senso de progresso do primitivismo para a sofisticação e identifica um ponto de continuum literário e cultural dentro da literatura ameríndia independente da chegada dos europeus ao continente.

Este descolamento das classificações de gênero da cultura dominante também acolhe importantes elementos mitológicos da cultura oral dentro da literatura escrita, como a figura do trickster, presente em várias formas na maioria das culturas nativas, onde os trickster tales são um gênero literário com a função de ensinar, divertir e transmitir mitos seminais. Escrito, importa a sintaxe e o humor da contação de histórias das culturas ameríndias para a poesia, o conto, o romance e o drama. O trickster ${ }^{5}$ toma diversas formas nas culturas aborígines: um ser amoral que toma a forma de humanos ou animais, que pode ser criativo ou destrutivo. Essa condição de benfeitor que age como bufão e aparece como coiote, lebre, corvo, em geral do sexo masculino, embora existam várias figuras femininas, é um glutão que se engaja em atividades obscenas e comportamentos tabu. Os contos o apresentam como vulgar, narcisista e subversivo, mas sua qualidade que mais no interessa aqui é a de transformista, de si próprio e do mundo, atribuindo-se a ele, inclusive a invenção da linguagem, a nomeação dos animais e das cores. Principalmente porque essas transformações transcendem o binarismo do pensamento ocidental que tende a classificá-lo como bom ou mau, sagrado ou vulgar, humano ou animal, por exemplo, subvertendo o pensamento cristão e as figuras deus e diabo, atribuídas aos nativos do continente e extrínsecas a suas culturas.

$\mathrm{O}$ próprio escritor aborígine age como um trickster ao transpor para uma das línguas dominantes, neste caso o inglês ${ }^{6}$, uma estrutura narrativa oral com origens em um tempo e uma cultura anteriores ao encontro colonial, portanto fora do alcance da cultura ocidental. Felizmente para nós, as culturas orais praticam um colapso temporal que mantém uma história tradicional sempre presente e atualizada, já que é uma história coletiva com traços de apropriação pessoal e local, permitindo que leitores não indígenas possam entender e acompanhar tanto os mitos quanto a cultura aborígine em sua inserção no mundo atual.

A importância da figura destaca-se na fundação, por um grupo de escritores indígenas residentes em Toronto, entre eles Tomson Highway, Daniel Moses e Lenore Keeshig-Tobias, do Comitê para Restabelecer o Trickster (CRET, 1986) 7 , com o objetivo político de reforçar a imagens dos habitantes nativos do Canadá junto à cultura dominante. A iniciativa compreendia a publicação de uma revista, performances, seminários, leituras e outras atividades visando a mudança de percepção sobre o indígena e sobre o escritor indígena, movimento que

\footnotetext{
4 Todos os textos referidos estão escritos em inglês, então se preferiu paráfrases a traduções, mesmo nos trechos entre parênteses.

5 Sobre o trickster, há o extensivo de Arnold Krupat, Para entender os trickster tales dos nativos norte-americanos. Trad. Eloína Prati dos Santos. In: SANTOS, Eloína (Org.), Perspectivas da Literatura Ameríndia no Brasil, Estados Unidos e Canadá. Feira de Santana: UEFS, 2003 p. 15-40; e a tese de Rubelise da Cunha, Anti-colonial tricks: storytelling figures of resistance in Lee Maracle, Thomas King and Tomson Highway (Tese de Doutoramento, PUCRS, 2005), que aborda a figura dentro da literatura indígena canadense.

6 Este trabalho focaliza apenas produção literária indígena contemporânea no Canadá inglês. Encontra-se um panorama da literatura indígena quebequense em OLIVIERI-GODET, Rita. "Quebec: o ameríndio e a controversa singularidade quebequense". In: A alteridade ameríndia na ficção contemporânea das Américas. Belo Horizonte: Fino Traço, 2013, p. $35-43$.

$7 \mathrm{O}$ bom humor da figura tradicional, muito presente nas narrativas ameríndias, reflete-se no comentário de que o grupo ficou conhecido como "Crétins", a partir da sigla do comitê.
} 
Rubelise da Cunha denomina de "indianização trickster do romance canadense", destacando o ativismo político da literatura indígena no país (2005, p. 188).

Lenore Keeshig-Tobias (Chippewa), escreve literatura infantil, é contadora de histórias, dramaturga e videomaker. Seus livros Bineshiinh dibaajmowin/Bird talk (1991) e Emma and the trees, Emma Minwaa Mitosh (1995), destinam-se a crianças bem pequenas, entre 4 e 8 anos de idade, e, são escritos em inglês e Ojibway, revelando a preocupação de começar a formar os índios contemporâneos desde pequenos dentro das culturas nativas, incluindo textos em línguas tribais para promover sua sobrevivência entre as novas gerações. Em 1993 ela partilhou com a filha, a ilustradora Polly, o Living Dream Book Award por Bird talk.

A maioria das escritoras ameríndias desenvolve um feminismo indígena em sua carreiras e obras, destacando que o feminismo euroamericano nem sempre as representa. Into the moon: heart, mind, body, soul: The Native Women's Writing Circle (1996), organizada por Keeshig-Tobias é uma coleção de histórias escritas em um workshop para mulheres indígenas, em que elas relataram tempos críticos em suas vidas, como situações de violência. A contação de histórias funciona como um processo de cura e publicar este tipo de relato restabelece o círculo do título, que dá força a todas as mulheres indígenas que sofreram e sofrem o lado mais violento do encontro de culturas. Quest For Fire: How The Trickster Brought Fire To The People (1991) é uma peça de teatro que traz uma das mais tradicionais histórias dos Chippewa, o presente mais importante do trickster para seu povo, o fogo. Keeshig-Tobias fez parte de um grupo que protestou contra a apropriação e a distorção das histórias nativas na escrita dos não nativos e em 1989 fez história ao discursar no Sindicato dos Escritores Canadenses pedindo aos escritores não nativos que "parassem de roubar as histórias nativas".

Daniel David Moses (Delaware) é poeta, dramaturgo, professor de escrita criativa e foi diretor artístico do Native Earth Performing Arts Centre. Seus dramas cobrem, entre muitos outros, a história de um amor trágico em Toronto, onde um fantasma, um coiote e uma família da reserva se mudam para a cidade (Coyote City, 199) e um épico do choque entre europeus e nativos na Ontário do século $17 \mathrm{com}$ ecos shakespeareanos (Brebuf's ghosts, 2000). Com montagens de suas peças premiadas em teatros profissionais e em instituições de ensino Moses levou o teatro canadense a um ponto sem retorno onde a literatura indígena não pode mais ser ignorada por nativos ou não nativos. Sua obra mostra um forte compromisso de interligar ambas as culturas e à narração das histórias que deram origem ao Canadá do ponto de vista do habitante nativo.
Tomson Highway destaca-se por ter mantido sua cultura e linguagem Cree e, oriundo de uma reserva e sujeito da experiência da internação escolar compulsória, ter conseguido excelência como escritor, dramaturgo e músico. Entre sua produção de sucesso se destacam, Kiss of the Fur Queen (1998), The Rez Sisters (1986) e o libreto da primeira opera em língua Cree, The Journey or Pimooteewin (2008). Highway costuma dizer que seus personagens sempre lhe falam em Cree, a língua que lhe é emocionalmente mais próxima, mesmo que ele escreva em inglês ou francês. Em suas peças de teatro Dry lips oughta move to Kapusaking (1989) e Rose (2003), Highway nos apresenta uma trickster configurada a partir das culturas Cree e Ojibway, onde o uso da língua Cree cria um diferencial que obriga ao leitor a usar as traduções para o inglês no rodapé dos livros, mas expõe os espectadores das montagens a um esforço maior de compreensão destas outras línguas e culturas. As duas obras denunciam a opressão e a violência contra as mulheres indígenas, encenando inclusive uma violenta cena de estupro.

Versões em Cree de Rez sisters e Dry lips oughta move to Kapuskasing já tinham sido oficialmente lançadas pela editora Fitzhenry and Whiteside, após suas performances em inglês desde 1980 e o autor encoraja outros escritores a usarem suas línguas nativas, muitas em extinção, e alguns exemplos têm surgido. Como o de Kevin Loring, de uma comunidade da Colúmbia Britânica, que ganhou o Governor Genereral Award de 2009 por sua peça Where the blood mixes, que inclui trechos na língua Salish. O jovem autor teria recitado um dos monólogos de Dry lips em uma aula de literatura canadense, onde se reconheceu, e que provocou sua necessidade de escrever sobre sua experiência. O Cree é a língua indígena mais usada no Canadá e seu número de usuários era estimado em cem mil falantes em 2006, ou seja, muitas línguas indígenas merecem ser contempladas dentro da característica do bilinguismo canadense, que mais comumente é um trilinguismo, composto pelo inglês, pelo francês e pelas inúmeras línguas de origem dos imigrantes.

A coiote nas histórias de Thomas King também é um personagem que toma várias formas humanas e animais, prega muitas peças e mostra inapelável bom humor. Ela age como uma mediadora entre a cultura indígena e a ocidental, entre índios imersos em suas culturas e índios aculturados e através de sonhos, danças, peidos, tenta "endireitar" o mundo, ou partes dele. Outra figura recorrente nas coyote stories de King, como os romances Medicine River (1989), Green Grass, running water (1993) ou os contos de One good story, that one (1993) e A short history of Indians in Canada (2005), é Primeira Mulher, memorável por "reencenar" a criação do mundo do ponto de vista nativo e "tratar todos os homens, Deus, 
Adão ou Noé, como meninos, que por serem lentos, birrentos ou assanhados, precisam de condescendência (SANTOS, 2007, p. 204) ${ }^{8}$.

Estes personagens "reencenam" a criação do mundo do ponto de vista do nativo. E não apenas de mitos de criação oriundos da tradição oral, mas em cenas ficcionais que narram os encontros entre Primeira Mulher e personagens bíblicos como Deus, Noé, Ahab ou Robinson Crusoe. A irreverência, o humor, as repetições, o uso de elementos das culturas aborígines se desenrolam como uma encenação, mais do que como uma narrativa tradicional. A instabilidade dos personagens, que mudam de nome, sexo e papel nos remetem a uma tradição oral em que cada narrador se apropria da história e, ao reproduzi-la, insere sua própria visão, elementos locais e temporais, tornando-a dinâmica e instável ao mesmo tempo em que se perpetua pela transmissão. Esses personagens e suas performances, se não estabelecem uma identidade aborígine - até porque não existe uma identidade unificada - contribuem para a desconstrução da superioridade do texto escrito e da identidade normativa. As cerimônias aborígines, mesmo as sagradas, incluem bastante humor, considerado por eles como uma estratégia de sobrevivência e de resistência.

A escritora Salish-Cree Lee Maracle é uma das mais prolíficas escritoras canadenses, ativista do Red Power Movement e do Liberation Support Movement, ela crê que "a acumulação de pesares" dos povos indígenas vem de longo tempo. "À̀s vezes me sinto como uma avó tola, armada de uma colher de chá, determinada a remover as três montanhas do caminho da liberação: a montanha do racismo, a montanha do sexismo e a montanha da opressão nacional" (1996, p. x). Uma das formas de fazer isso, para ela, é a autoficção, que lhe permite examinar as condições de vida da mulher indígena desde "um lugar profundamente pessoal" (p. xi), explícito em Bobi Lee, Indian rebel (1990) e em I am woman (1996), onde a alternância entre poesia e prosa nos aproxima da oralidade das narrativas indígenas, pois seus textos são dirigidos a outras mulheres indígenas imersas na discriminação de gênero, além da racial. A figura do trickster em Maracle é um corvo. No romance Ravensong (1993), o corvo também tenta "consertar" o mundo e estabelecer uma ponte entre a cultura nativa e a não nativa em um momento de grande crise - a epidemia de gripe dos anos 50, relacionada à perda do espírito comunitário entre os Salish e à importação de males dos brancos, como o suicídio (que se tornou comum nas comunidades indígenas devido à perda da autoestima $\mathrm{e}$ dos valores tribais). Stacey cruza a ponte para a cidade branca diariamente, para ir à escola e de lá trazer novos conhecimentos, uma vez que os anciãos estão morrendo de gripe. Depois da morte de sua avó, uma canção lhe invade os sonhos com murmúrios do passado. Raven, dividia entre as duas culturas, representada pela ponte que separa a reserva da cidade onde estão a escola, os estabelecimentos comerciais e a discriminação. A jovem Stacey, apoiada nas canções de sua falecida avó, que invadem seus sonhos, precisa cruzar a ponte metafórica e saber tirar o melhor proveito das duas culturas, combinar os saberes das duas culturas.

As avós, em geral sem nome próprio, aparecem em inúmeras histórias nativas como seres dotados de sabedoria e conselheiras dos mais jovens sobre como fugir do perigo, enfrentar monstros e usar mágica. Elas também têm a capacidade de se transformar em animais que dão conselhos. Esta avó não é mesma das relações familiares dos não índios, mas mulheres mais velhas em geral, respeitadas por sua grande sabedoria como representantes da mãe-terra. Elas são contadoras das histórias tradicionais e perpetuadoras das culturas tribais ${ }^{9}$.

Lee Maracle trata da questão da violência contra a mulher indígena em Bobbi Lee, Indian Rebel, através de suas memórias sobre seu ativismo em movimentos antiguerra e antirracismo, que, na época, aliado ao uso de drogas, a deixou cética quanto à possibilidade de entendimento com não nativos. Originalmente publicada em 1975, Indian Rebel é totalmente revisado pela autora e sua nova perspectiva de vida resulta em I am a woman (1996) em que ela propõe o fim do racismo, a convivência interracial pacífica e tece seu conceito de feminismo indígena, visto com outros olhos a partir de práticas de descolonização.

A questão da mestiçagem e a história de opressão contra as mulheres indígenas é examinada ainda por Janice Acoose (Sakimay) em Iskwewak - kah 'ki yaw ni wahkomakanak. Neither Indian princess nor easy squaw, um título que coloca em primeiro lugar a sua língua nativa e em segundo o inglês. Ela ostenta com orgulho o termo mestiça (Métis), baseada no famoso romance autobiográfico de Maria Campbell, Halfbreed (1973), um livro sobre ser métis, audacioso para a época. Ela cita documentação abundante da história e da literatura eurocanadenses sobre a sobrevivência desse estereótipos sobre as mulheres indígenas que chegaram até nossos dias (1995, p. 44-45). Segundo ela, isso contribui para

\footnotetext{
8 Análise detalhada das obras de King Green Grass runing water (1993a) e One good story that one (1993b) em A criação do mundo segundo Tomas King: uma performance visionário-identitária. In: LOPES, Luiz Paulo de Moita; DURÃO, Fábio Ackelrud; ROCHA, Roberto Ferreira da (Orgs.). Performances: estudos de literatura em homenagem a Marlene Soares dos Santos. Rio de Janeiro: Contra Capa, 2007, p. 201-215.

9 Em seu trabalho A presença das grandmothers nas temporalidades das narrativas autobiográficas de Beverly Hunfry Woolf, Lee Maracle e Maria Campbell, Alvany Guanaes oferece um estudo detalhado desta figura em sua introdução (p 13-19) e analisa as diferentes abordagens do papel das avós na autoficção das três escritoras indicadas (Tese de Doutoramento, USP, 2011).
} 
"perpetuar a violência sexual, física, verbal e psicológica" contra as mulheres indígenas. Até hoje elas precisam lutar contra uma combinação de racismo e sexismo, legal e politicamente, enquanto reivindicam seu papel central como guardiãs da cultura e autonomia sobre seus corpos (p. 58). Como prova da injustiça da permanência desse estigma, Acoose percorre uma lista de autoficções de mulheres indígenas canadenses que a precederam: Emma LaRoque, Beatrice Culleton, Jeanette Armstrong, Lee Maracle, Ruby Slipperjack, Marie Anneharte Baker, Beth Cuthand, Louise Halfe (p. 39), além de Patricia MontureOkanee, Monica Goulet, Marylyn Dumont, Mary Sky Blue, uma lista de "mulheres que sobreviveram para contar suas histórias e encontram solidariedade e conforto entre suas irmãs" (p. 104). Elas compõem, com vários outros nomes, uma lista que corrobora a possibilidade de se ministrar um curso exclusivamente sobre autobiografia e mulher indígena no Canadá, ao mesmo tempo em que afirma a validade de usar a língua inglesa para representar suas experiências, renomear e redefinir seus povos originais (p. 58) ${ }^{10}$. Mas seu uso da língua inglesa não é despido de subversão, como no uso de caixa baixa em english, canadian literature, north america, para "desconstruir o centro autoritário do "patriarcado cristão branco canadense"” (p. 13).

Os povos nativos também estão produzindo cinema de qualidade, de adaptações, como a de Medicine River, de Thomas King, a documentários sobre conflitos contemporâneos nas comunidades tribais do Canadá. Medicine River (1993), o filme, com o subtítulo De volta às origens na versão brasileira (disponível no Netflix), é uma comédia sobre um foto jornalista que retorna à sua Medicine River de origem depois de vinte anos, para o funeral de sua mãe. O velho amigo Harlen Bigbear o toma sob sua proteção e o arrasta para várias situações hilárias que acabam por mudar sua vida radicalmente. $O$ contraste entre aqueles que se afastaram da vida dentro dos valores tribais tradicionais e aqueles que a abandonaram, por mais cômico que seja, é ao mesmo tempo uma crítica e uma possibilidade de reconciliação para o índio contemporâneo.

Algumas jovens cineastas também investem na situação da mulher indígena por encontrarem resquícios de sexismo e de sectarismo importados da cultura branca dentro das próprias tribos. Tracey Deer (Mohawk) produziu dois filmes, Mohawk girls (2005) e Club Native (2008) sobre a complexidade das questões de indentidade dentro da Reserva Mohawk em Kahnawake, onde a interracialidade é questionada pelo conselho de anciães, onde mulheres têm assento, mas que empregam conceitos racistas estabelecidos no período colonial por brancos. No primeiro documentário, Deer retrata a vida de duas adolescentes confinadas na reserva pelas rígidas regras da comunidade, mas que revelam suas esperanças e decepções sobre crescer indígena no século XXI. As Mohawk girls devem seguir regras não escritas, mas impostas: não casar com branco e não ter filho com branco, sob pena de perderem o status tribal para si e para seus descendentes. Em Club Native o foco são quatro mulheres julgadas pelas infames quotas sanguíneas, usadas até a metade do século XX para determinar a indianidade dos índios, agora impostas por seus pares, com a perda do status tribal e direitos como manter seus filhos nas escolas, possuir propriedade e ser enterrada na reserva. As regras separam famílias e geram sofrimento em mulheres que mantém conexão com a língua e a cultura de seu povo $^{11}$.

Estes poucos autores e títulos apresentados no espaço deste artigo pretendem despertar o interesse de professores e alunos de literaturas estrangeiras no Brasil, e leitores em geral, para a riqueza, o volume, a variedade, a qualidade e a pertinência da literatura indígena no Canadá (e por extensão, em todo o continente americano). Mesmo este panorama limitado permite afirmar o que atestam inúmeras antologias, ensaios teóricos, romances, poemas, peças de teatro, filmes, ilustrações, teses, cursos acadêmicos e outras formas de expressão: que os indígenas canadenses estão produzindo obras, por vezes com a ajuda dos tricksters e das avós, que trabalham para regenerar a autoestima e regatar a história dos povos e das línguas indígenas apagadas e reprimidas por vários séculos e para disseminar sua cultura no mainstream não indígena.

Para os não nativos a riqueza mitológica e de valores dos povos indígenas expande o cânone das culturas euroamericanas e as resgata da soberba da superioridade racial, podendo nos levar a sociedades menos intolerantes e genuinamente multi e interculturais, vencido o preconceito ou o descaso contra o desconhecido.

\section{Referências}

ACOOSE, Janice. Iskwewak Kah 'Ki Yaw Ni Wahkomakanak. Neither Indian princess nor easy squaw. Toronto: Women's Press Suit, 1995.

BHABHA, Homi K. How newness enters de world. The location of culture. London/New York: Routledge, 1994, p. 212-235.

DA CUNHA, Rubelise. Anti-colonial tricks: storytelling figures of resistance in Lee Maracle, Thomas King and Tomson Highway. 2005. Tese (Doutorado em Linguística e Letras) Faculdade de Letras, PUCRS, Porto Alegre, 2005.

\footnotetext{
${ }^{10}$ Análise detalhada da obra de Acoose em: SANTOS, Eloína. "Can we speak of a Native American critical theory? In: HANCIAU, Núbia (Org.) Brasil/Canadá: visões, paisagens e perspectivas do Ártico ao Antártico. Rio Grande: Abecan-Furg, 2006, p. 93-100.

${ }^{11}$ Análise mais ampla dos dois filmes em: SANTOS, Eloína. Mulheres Mohawk entre dois mundos: como pertencer ao clube com regras imperiais no século XXI? Interfaces Brasil/Canadá, Niterói, n. 12, p. $185-200,2011$
} 
GUANAES, Alvany Rodrigues Noronha. A presença das grandmothers nas temporalidades das narrativas autobiográficas de Beverly Hunfry Woolf, Lee Maracle e Maria Campbell. Tese (Doutorado em Estudos Linguísticos e Literários em Inglês) - Faculdade de Filosofia, Letras e Ciências Humanas, USP, São Paulo, 2011.

HOY, Helen. How should I read these? Native women writers in Canada. Toronto/Buffalo/London: University of Toronto Press, 2001.

KING, Thomas. Godzilla vs post-colonial (1990). In: SUGARS, Cynthia (Ed.). Unhomely states: Theorizing English-Canadian postcolonialisn. Peterborough/Ontario: Broadview Press, 2004. p. 183-190.

MARACLE, Lee. I am woman: a Native perspective on sociology and feminism. Vancoucer: Press Gang, 1996.

MARACLE, Lee. Post-colonial imagination (1992). In: SUGARS, Cynthia (Ed.). Unhomely states: Theorizing EnglishCanadian postcolonialisn. Peterborough/Ontario: Broadview Press, 2004, p. 204-208.
MOHANTY, Chandra. On race and the voice for liberal education for the 1990s. Cultural Critique, 14, p. 179-208, Winter 1989-90.

SANTOS, Eloína. Can we speak of a Native American critical theory? In: HANCIAU, Núbia Jacques (Org.). Brasil/Canadá: visões, paisagens e perspectivas do Ártico ao Antártico. Rio Grande: Abecan/Furg, 2006, p. 93-100.

SANTOS, Eloína. A criação do mundo Segundo Thomas King: uma performance visionário-literária. In: LOPES, Luiz Paulo de Moita; DURÃO, Fábio Ackelrud; ROCHA, Roberto Ferreira da (Orgs.). Performances: estudos de literatura em homenagem a Marlene Soares dos Santos. Rio de Janeiro: Contra Capa, 2007, p. 201-215.

Recebido: 30 de outubro de 2015 Aprovado: 05 de janeiro de 2015

Contato: eloinaprati@gmail.com 